\title{
Evaluation of optical techniques for characterising soil organic matter quality in agricultural soils
}

Article

Accepted Version

Fernández-Romero, M.L., Clark, J.M., Collins, C.D., ParrasAlcántara, L. and Lozano-García, B. (2016) Evaluation of optical techniques for characterising soil organic matter quality in agricultural soils. Soil and Tillage Research, 155. pp. 450460. ISSN 0167-1987 doi:

https://doi.org/10.1016/j.still.2015.05.004 Available at https://centaur.reading.ac.uk/40551/

It is advisable to refer to the publisher's version if you intend to cite from the work. See Guidance on citing.

Published version at: http://dx.doi.org/10.1016/j.still.2015.05.004

To link to this article DOI: http://dx.doi.org/10.1016/j.still.2015.05.004

Publisher: Elsevier

All outputs in CentAUR are protected by Intellectual Property Rights law, including copyright law. Copyright and IPR is retained by the creators or other copyright holders. Terms and conditions for use of this material are defined in the End User Agreement. 


\section{CentAUR}

Central Archive at the University of Reading

Reading's research outputs online 
1 EVALUATION OF OPTICAL TECHNIQUES FOR CHARACTERISING SOIL

2 ORGANIC MATTER QUALITY IN AGRICULTURAL SOILS

3

4 M.L. Fernández-Romero ${ }^{\mathrm{a}}{ }^{*}$, J.M. Clark $^{\text {b }}$, C.D. Collins ${ }^{\text {b }}$, L. Parras-Alcántara ${ }^{\text {a }}$, B. Lozano-

5 García ${ }^{a}$

6

$7{ }^{a}$ Department of Agricultural Chemistry and Soil Science, Faculty of Science, Agrifood Campus

8 of International Excellence (ceiA3), Universidad de Córdoba, 14071 Cordoba, Spain

$9{ }^{\mathrm{b}}$ Soil Research Centre, Department of Geography and Environmental Sciences, School of

10 Human and Environmental Sciences, University of Reading, Whiteknights, RG6 6AB, Reading,

$11 \mathrm{UK}$

12

13

14

15

16

17

18

19

20

21 *Corresponding author: María Luisa Fernández-Romero. Tel.: +34 667964310;

22 +44 7790399784. E-mail addresses: a52ferom@uco.es; fdezmarialuisa@gmail.com 
24 Soil organic matter (SOM) is one of the main global carbon pools. It is a measure of soil quality as its presence increases carbon sequestration and improves physical and chemical soil properties. The determination and characterisation of humic substances gives essential information of the maturity and stresses of soils as well as of their health. However, the determination of the exact nature and molecular structure of these substances has been proven difficult. Several complex techniques exist to characterise SOM and mineralisation and humification processes. One of the more widely accepted for its accuracy is Nuclear Magnetic Resonance (NMR) spectroscopy. Despite its efficacy, NMR needs significant economic resources, equipment, material and time. Proxy measures like the fluorescence index (FI), cold and hot-water extractable carbon (CWC and HWC) and SUVA-254 have the potential to characterise SOM and, in combination, provide qualitative and quantitative data of SOM and its processes. Spanish and British agricultural cambisols were used to measure SOM quality and determine whether similarities were found between optical techniques and ${ }^{1} \mathrm{H}-\mathrm{NMR}$ results in these two regions with contrasting climatic conditions. High correlations $(\mathrm{p}<0.001)$ were found between the specific aromatic fraction measured with ${ }^{1} \mathrm{H}-\mathrm{NMR}$ and SUVA-254 (Rs=0.95) and HWC (Rs=0.90), which could be described using a linear model. A high correlation between FI and the aromatics fraction measured with ${ }^{1} \mathrm{H}$ -

\footnotetext{
Abbreviations: (SOM) Soil organic matter; (NMR) Nuclear magnetic resonance; (FI) Fluorescence index; (CWC) Cold-water extractable carbon; (HWC) Hot-water extractable carbon; (LOI) Loss of ignition; (DOM) Dissolved organic matter; (DOC) Dissolved organic carbon; (EEM) Excitation-emission matrix; (GS-UK) Soil with a grass cover, United Kingdom; (CC-UK) Cereal crops from United Kingdom; (CC-ES) Cereal crops from Spain; (OG-ES) Olive grove from Spain; (HIX) Humification index; (BIX) Biological/autochthonous index; (RU) Raman units; (SUVA-254) Specific absorbance at $254 \mathrm{~nm}$
} 
NMR (Rs=-0.976) was also observed. In view of our results, optical measures have a potential, in combination, to predict the aromatic fraction of SOM without the need of expensive and time consuming techniques.

KEYWORDS: SOM quality; hot-water extractable carbon; cold-water extractable carbon; fluorescence index; EEM; SUVA- $254 ;{ }^{1} \mathrm{H}-\mathrm{NMR}$; aromatic fraction.

\section{Introduction:}

\subsection{The importance of organic matter}

Soil organic matter (SOM) is composed of organic residues that are originated from plant and animal remains and microbial products at different stages of decomposition or humification (Hur et al., 2013). Additionally, it is one of the main global carbon pools, storing three times more carbon than living organisms or the atmosphere (Fischlin et al., 2007; Brevik, 2012). Aside from carbon sequestration, SOM is also a measure of soil quality because of the beneficial function it has on a variety of soil processes. For instance, it reduces erosion and, therefore, increases crop production by increasing the elasticity and resistance to deformation and compactability as well as porosity and water retention (Sellami et al., 2008; Paradelo and Barral, 2013). Increased water retention decreases potential runoffs by improving water infiltration in to soils and provides a store of water for plant uptake, buffering against moisture and rainfall fluctuations (Lal, 2004). This is of importance considering that the lack of water retention leads to a change in the hydrological patterns of agricultural areas and promotes the quantity and severity of floods and water-led erosion. Also, SOM leads to an increased vegetative cover, which ultimately reduces soil erosion (Cerdà, 1998, 2000; Novara et al., 2011; Zhao et al., 2013). Carbon mineralisation is crucial in SOM dynamics and along with carbon input, determines how much carbon accumulates in soil and releases nutrients that are essential for plant growth. Factors that affect mineralisation are the size of 
labile carbon, environmental conditions and the local microbial community (Zhao et al., 2008; Li et al., 2013). SOM and soil assemblage; SOM decomposition and transport by organisms contribute to soil stabilisation and the improvement of soil structure (Brevik et al., 2015). Moreover, SOM quantity has been directly related to the preservation of soil aggregates, which in turn reduces soil erodibility (Novara et al., 2011). Also, the direct processing of SOM along with its decomposition contribute to the improvement of soil chemical properties and stability (Brevik et al., 2015). Therefore, optimal quantities of SOM improve structure, water retention, and nutrient holding capacity of soils, which has an effect in multiple aspects of the soil system. These are essential considering the wider context of Earth System, as SOM conservation techniques have been proven to improve the fertility of degraded soils of a wide variety of ecosystems that are the main resource of large communities of developing areas of our planet, as well as have an influence on biogeochemical cycles and climate change mitigation (Batjes, 2014; Saha et al., 2014; Srinivasarao et al., 2014).

\subsection{SOM carbon fractions and their importance}

SOM has been conceptualised as containing three pools, with different residence/turnover times (Trumbore, 2000). These pools are the active SOM (living biomass of microorganisms and partially decomposed residues; associated with 1 year turnover); the slow SOM (resistant plant material; associated to a turnover from years to centuries); and passive SOM (humic substances and inert organic matter), which has been traditionally associated with longer residence time (thousands of years) and more stability. Some authors consider that the inert organic matter should not be considered as part of the passive pool, but as a fourth pool (Trumbore, 1997; Ohno, 2002; Agren and Bosatta, 2002; Sparks, 2003; Bell and Lawrence, 2009; Dungait et al., 2012). Although the traditional view has been that decomposition led to complex molecules 
that were very stable as a result of their structure; it has recently been known that environmental conditions, organo-mineral associations and other processes influence more in SOM stability than structure, which only plays a secondary role. As a result of this new view, recent research has found that humic substances, which have always been considered high molecular mass polymers, could be simpler than originally thought (Kleber and Johnson, 2010; Schmidt et al., 2011). Still, their structure is on discussion and the separation of SOM into fractions with different turnovers remains a major challenge (Kleber, 2010; Schmidt et al., 2011; Schrumpf and Kaiser, 2015).

Non-humic substances are composed by microbial biomass, decomposable plant material (active SOM); and resistant plant material, mainly waxes, lignified tissues and polyphenols (slow SOM) (Dungait et al., 2012). Microbial biomass has been used for comparing natural and degraded ecosystems and as an early indicator of soil processes, fertility and health (García-Gil et al., 2000; Brevik, 2009; Chen et al., 2013).

\subsection{Current SOM quality measurements. Challenges}

Measures such as \% Organic Matter measured by Loss of Ignition (LOI) are useful, popular and inexpensive methods to determine bulk SOM (Luke et al., 2009; Salehi et al., 2011). However, some studies have concluded that bulk SOM measurements cannot be used, on their own, as a representative indicator of carbon in soil due to their limitations (Koarashi et al., 2005; Salehi et al., 2011).

Humic substances have also been measured to determine soil quality, as their presence has been associated with a higher quality of soils as stated in section 1.2. Their study is relevant in agricultural soils, as they increase crop yield and root dry weight, although this response is not fully understood (Rose et al., 2014). Therefore, the determination and characterisation of humic substances gives essential information of the maturity and stresses of soils as well as of their health. 
117 Traditionally, alkali and acid abstraction methods have been used, to later interpret the 118 chemistry of the extracted functional groups (Olk and Gregorich, 2006). Afterwards, 119 these were combined with other complex techniques that enabled scientists to obtain new information on the structure and dynamic associations of humic substances (Sutton and Sposito, 2005; Schmidt et al., 2011). Despite these advances, SOM dynamics and cycling still have many questions to answer, with models differing in SOM fluxes results for the future, due to their sensitivity to SOM turnover time assumptions

124 (Schmidt et al., 2011). There are a number of powerful but complex and expensive techniques that have been used for the study of soil fluxes (Helal et al., 2011). The economic resources needed, along with the time required to prepare the samples and conduct the analyses, make its use with a large number of samples difficult and delays experiments, while more work is still needed to accurately determine and define the molecular structures and linkages between the SOM components (Weishar et al. 2003; Helal et al., 2011).

Nuclear Magnetic Resonance (NMR) spectroscopy is a non-destructive technique that is valuable for the characterisation of SOM and humification processes, providing information on static and dynamic properties of molecules. This is due to its high performance to assess intermolecular interactions. The relationship between SOM, contaminants and metals can also be studied with NMR (Cardoza et al., 2004). Of the the components of the substance, and gives a semi-quantitative notion of aromatic, aliphatic and carboxylic groups (Hemminga and Buurman, 1997). One of the main drawbacks of this technique is the quantity of economic resources that are necessary for its regular application in research laboratories/centres. This is due to the expensive 
deuterated solvents and NMR tubes, as well as the expensive equipment and significant sample preparation that are required (Weishar et al., 2003; Cardoza et al., 2004; MIT, 2008). Also, the technique is time consuming not only when measuring, but when interpreting 2-D or 3-D data resulting from it (Cardoza et al., 2004). Simpler methods quality for the characterisation of SOM are required.

\subsection{Proxy measures. Opportunities to improve the ability to characterise SOM}

Water extractable carbon is the most active component in the carbon cycle. Its quantity and biological nature is affected by the extraction temperature (Bu et al., 2010). Hotwater extractable carbon (HWC) contains simple compounds such as microorganisms, soluble carbohydrates and other compounds that account for the labile fraction of SOM (Ghani et al., 2003). HWC responds to land use changes in the short term and has been used to detect the effects of different land management practices and for determining the effects of soil amendments such as biochar or agricultural residues (Leifeld and Kögel-Knabner, 2005; Uchida et al., 2012; Alburquerque et al., 2014; FernándezRomero et al., 2014). For these reasons, it has been proven useful to obtain information about soil quality (Ghani et al., 2003; Xue et al., 2013).

Fluorescence has become popular because of its potential to characterise SOM and study humic substances, as it is non-destructive, simple, non-separative and accurate. As a result, it has been used for determining the compositional and structural properties of SOM (Chen et al., 2003; Senesi and D’Orazio, 2005; Sun et al., 2007; Kwiatkowska et al., 2008; Henderson et al., 2009; Hur and Kim, 2009; Tang et al., 2011). The intensity and position of the peaks detected in the spectra are unique to each substance structural and functional characteristics. For instance, higher fluorescence intensities are related to a higher humification (Martins et al., 2011). 
167 The Fluorescence Index (FI) was developed to assess different properties of dissolved organic matter (DOM). It was defined by McKnight et al. (2001) as the ratio of emission intensities at $450-500 \mathrm{~nm}$ excited at $370 \mathrm{~nm}$. The $450 \mathrm{~nm}$ point was chosen for specific characteristics of the experiment. Later, Cory et al. (2010) modified the ratio to $470-520 \mathrm{~nm}$ to reflect corrections specific to the instruments used. This index has been correlated to the aromaticity of DOM (Korak et al., 2014).

173 Fluorescence spectroscopy can be used in combination with UV-Visible spectroscopy to characterise humic substances, as absorbance measures transitions from the ground state to the excited state, as opposed to fluorescence spectroscopy (Skoog et al., 2007). Its spectra are usually uniform and provide with qualitative data when a specific $\left(\mathrm{SUVA}_{-254}\right)$ has been recognised as a method to determine SOM aromaticity (Fuentes et al., 2006; Chow 2006). This parameter is very useful for assessing the nature of the general composition of dissolved organic carbon (DOC), due to its high correlation with it (Weishar et al., 2003).

Considering what has been described in sections 1.3 and 1.4 above, both the fluorescence and NMR techniques can be used in combination to determine the humic substances properties and the degree of aromaticity; while HWC could contribute further to the understanding of soil quality, given its usefulness to detect the biodegradation of soil biochemical properties (Ghani et al., 2003; Saab and MartinNeto, 2007; González-Pérez et al., 2007).

As an illustrative and additional way to characterise and represent some of the analyses conducted and the results obtained, Excitation-Emission Matrix (EEM) spectra have been plotted. These provide information on the relative intensity of fluorescence at different excitation and emission wavelengths regions in a fast manner that is also easy 
to interpret (Coble, 1996). Several peaks have been identified that are used to describe EEM fluorescence spectra. Peak A and C refer to humic peaks. Peak A is referred to as UVC-excited and is located at an excitation wavelength $\left(\lambda_{\mathrm{Ex}}\right)$ between $240-260 \mathrm{~nm}$ and an emission wavelength $\left(\lambda_{\mathrm{Em}}\right)$ between $400-460 \mathrm{~nm}$. Peak C, also referred to as UVAexcited; is located at a $\lambda_{\text {Ex }}$ between $320-360 \mathrm{~nm}$ and a $\lambda_{\mathrm{Em}}$ between $420-460 \mathrm{~nm}$. There are also peaks that indicate biological activity material (peaks B and T, which are defined as tyrosine-like and tryptophan-like peaks respectively). B has $\lambda_{\mathrm{Ex}}$ of 270-280 $\mathrm{nm}$ and $\lambda_{\text {Em }}$ of 300-315 $\mathrm{nm}$ whereas T has $\lambda_{\text {Ex }}$ between $270-280 \mathrm{~nm}$ and $\lambda_{\mathrm{Em}}$ of 345$360 \mathrm{~nm}$ (Birdwell and Engel, 2010).

\subsection{Aim/objective of this study}

The aim of this study was to evaluate the use of fluorescence spectroscopy to measure SOM quality (specifically the grade of humification). The specific objectives were: (1) characterise water extractable SOM quality using liquid state ${ }^{1} \mathrm{H}-\mathrm{NMR}$; (2) characterise the quality of water extractable organic matter using fluorescence spectroscopy and UVVIS; (3) compare measures of quantity and quality of water extractable organic matter with the specific organic matter fractions measured by ${ }^{1} \mathrm{H}-\mathrm{NMR}$ like aromaticity. If robust relationships and similarities between optical measures and ${ }^{1} \mathrm{H}-\mathrm{NMR}$ are found, there may be potential for fluorescence spectroscopy as a fast and more cost-effective method of organic matter characterisation.

\section{Materials and methods}

\section{1. $\quad$ Field sites description}

Cambisols were sampled in two regions with contrasting climatic conditions;

Andalusia (South Spain) and Berkshire (South East England) (Table 1). Berkshire has a temperate climate, characterised generally by relatively mild winters and summers and rainfall throughout the year. The annual mean temperature ranges from $6.7^{\circ} \mathrm{C}$ and 
$217 \quad 14.5^{\circ} \mathrm{C}\left(30\right.$ years, annual mean temperature: $\left.10.5^{\circ} \mathrm{C}\right)$ and the average annual rainfall is $218 \quad 635.4 \mathrm{~mm}$ (UK Met Office, 2014).

219 Andalusia has a Mediterranean climate, which characteristics are hot and dry summers 220 contrasted with cool and wet winters. In the province of Cordoba (Hinojosa del Duque 221 and Pozoblanco), the annual mean temperature is $17.6^{\circ} \mathrm{C}$ and the average annual 222 rainfall is $536 \mathrm{~mm}$ (Aemet, 2014). As for the province of Jaen (Torredelcampo), its annual mean temperature is $16.2{ }^{\circ} \mathrm{C}$ and the average annual rainfall is $646.3 \mathrm{~mm}$

224 (REDIAM, 2007).

225

226

In Berkshire, samples were collected from University of Reading Farms at Sonning, Arborfield and Shinfield. The site sampled at Sonning (GS-UK-1) has been covered with grass for over 15 years. Arborfield (CC-UK-1) was permanent pasture until autumn 2012, and has been subsequently drilled with wheat or winter barley. Shinfield (CC-UK-2) has been in an arable rotation for over 20 years and sown with either winter wheat, maize or spring barley.

In Andalusia, soil samples were collected between the provinces of Jaen (Torredelcampo) and Cordoba (Hinojosa del Duque, Pozoblanco) that were managed with conventional tillage of cereals and olive crops. CC-ES-3 was managed with a wheat-barley-fallow cycle, whereas the other sites (CC-ES-1 and CC-ES-2) were covered by wheat crops throughout the year. OG-ES-1, OG-ES-2, and OG-ES-3 were covered by olive grove.

\section{2. $\quad$ Sample collection and preparation}

Soil samples were collected from each horizon. Total soil depths are included in Table 2. Only the first horizon from each soil (specified in section 2.3) was used for the analyses. Samples were air dried and sieved with a $2 \mathrm{~mm}$ sieve. 
243 Cold and hot water extractable carbon were determined following Ghani et al. (2003).

244 This consists in a cold and a hot extraction of the supernatant of the samples (room temperature and $80^{\circ} \mathrm{C}$ respectively). To do this, $30 \mathrm{ml}$ of ultrapure water was added to $3 \mathrm{~g}$ of soil. Then, there was a 30 -minute extraction in a shaker at $20^{\circ} \mathrm{C}$. After this, the

247 sample was centrifuged during 20 minutes at $3500 \mathrm{rpm}$. Once this was done, the supernatant was extracted (cold extraction) and analysed (DOC). The resulting pellet was used for the rest of the steps. $30 \mathrm{ml}$ of ultrapure water were added to the pellet, which was then shaken on a Vortex to mix the ultrapure water with the pellet. The sample was then left in a bath at $80{ }^{\circ} \mathrm{C}$ during 16 hours. The sample was centrifuged at $3500 \mathrm{rpm}$ during 20 minutes and was filtered with a $0.45 \mu \mathrm{m}$ cellulose nitrate filter (hot extraction). The filtered supernatant was analysed for DOC, fluorescence, absorbance and NMR.

255

The techniques that were compared in this study were applied to the first horizon of each soil sample, as this was considered sufficient for the purposes of comparing these techniques. This horizon was at different depths depending on the soil sample (at $12 \mathrm{~cm}$ in GS-UK-1; $10.5 \mathrm{~cm}$ in CC-UK-1; $5.7 \mathrm{~cm}$ in CC-UK-2; $15 \mathrm{~cm}$ in CC-ES-1; $20 \mathrm{~cm}$ in CC-ES-2; $30 \mathrm{~cm}$ in CC-ES-3; $10 \mathrm{~cm}$ in OG-ES-1; $10 \mathrm{~cm}$ in OG-ES-2 and $18 \mathrm{~cm}$ in OGES-3).

Fluorescence of all the hot water extracts was measured in a Varian Eclipse Fluorescence spectrophotometer (Agilent Technologies, Santa Clara, CA, USA) at an emission wavelength from 300 to $600 \mathrm{~nm}$ at 5-nm increments and an excitation of 240$450 \mathrm{~nm}$ at $5-\mathrm{nm}$ increments. All samples were run in $1 \mathrm{~cm}$ quartz cuvettes and in triplicate. 
FI was calculated as the ratio of intensities at 450 over $500 \mathrm{~nm}$ with an excitation of $370 \mathrm{~nm}$, as described by Cory et al. (2010). McKnight et al. (2001) introduced this index approach for the characterization of the fulvic and fraction of DOM. The Humification Index (HIX) was calculated with the following formula:

$\left(\sum \mathrm{I}_{435 \rightarrow 480}\right) /\left(\sum \mathrm{I}_{300 \rightarrow 345}\right)+\left(\sum \mathrm{I}_{435 \rightarrow 480}\right)$

where I is the fluorescence intensity at each wavelength (modified of Zsolnay et al., 1999 by Ohno, 2002).

The Biological/Autochthonous Index (BIX) has been calculated as the ratio of intensities at $380 \mathrm{~nm}$ over $430 \mathrm{~nm}$ with an excitation of $310 \mathrm{~nm}$, as described by Huguet et al. (2009). This index assesses the relative contribution of autochthonous DOM in water and soil samples.

A subsample of the HWC extract was frozen and subsequently freeze-dried to remove all the water present. Deuterium oxide was added as a solvent to avoid disruptions in the spectrum, as other solvents have a proton signal that causes disruptions, as demonstrated by Cardoza et al. (2004), prior to a second freezing and a second freezedrying. This second stage of freezing-freeze-drying was used to avoid that $\mathrm{H}_{2} \mathrm{O}$ peaks interfered in the spectra. After that, deuterium oxide $(100 \%$, density of $1.107 \mathrm{~g} / \mathrm{ml}$ at $25^{\circ} \mathrm{C}$ ) was added again as a solvent to conduct the NMR tests. NMR was measured in 1.5-1.7 ml of sample with a Bruker Avance III 700 MHz NMR spectrometer (Bruker Corporation, Billerica, MA, USA). The deuterium oxide peak was used as a calibration reference and placed in $4.75 \mathrm{ppm}$.

Absorbance of all the hot water extracts was measured with a Varian Cary 300 UVwith $1 \mathrm{~nm}$ intervals using a $1 \mathrm{~cm}$ cuvette. 
SUVA- 254 has been used for this study. This is the absorbance at $254 \mathrm{~nm}$ divided by the

291 DOC concentration (of the hot water extracts). Values are expressed in $1 \cdot \mathrm{mg}^{-1} \cdot \mathrm{m}^{-1}$.

292

293

294

DOC of the cold and hot water extracts was calculated with a Shimadzu TOC 5000 total organic carbon analyser (Shimadzu Corporation, Kyoto, Japan). Standards were calculated using Stock solutions of 1,000 ppm.

$\%$ Organic matter measured by LOI was calculated using a modified version of Hieri et al. (2001). A soil sample of $10 \mathrm{~g}$ was heated at $105^{\circ} \mathrm{C}$ for 24 hours. Then, the sample was weighted again $\left(\mathrm{w}_{1}\right)$ and heated in a Muffle furnace at $550{ }^{\circ} \mathrm{C}$ for 16 hours to ignite the organic matter. The sample was weighted after this $\left(\mathrm{w}_{2}\right)$ and the $\%$ of organic matter was obtained by weight difference between $\mathrm{w}_{1}$ and $\mathrm{w}_{2}$.

Soil $\mathrm{pH}$ was determined in 1:2.5 soil to water ratio. Texture was determined by laser granulometry, using a Coulter LS 230 (Beckman/Coulter Inc. Brea, CA, USA). This technique uses polarised light at three different wavelengths $(450 \mathrm{~nm}, 600 \mathrm{~nm}$ and $900 \mathrm{~nm}$ ) to analyse the particle size distribution specifically in the $0.04 \mu \mathrm{m}$ to $0.4 \mu \mathrm{m}$ range.

EEM fluorescence spectra were obtained by collecting a series of emission scans of $\lambda_{\text {Ex }}$ $240-450 \mathrm{~nm}$ at $5 \mathrm{~nm}$ intervals and $\lambda_{\mathrm{Em}} 300-600 \mathrm{~nm}$, also at $5 \mathrm{~nm}$ intervals. EEM spectra were plotted using RStudio v0.98.1091 (Rstudio Inc., Boston, MA, USA). Intensities are reported in Raman units (RU). Raman scattering was mitigated subtracting blanks that had been collected on ultrapure water from each spectrum.

\section{4. $\quad$ Statistical methods}

Data were tested for normality to verify the model assumptions. As the data failed the normality test, non-parametric tests were used. The effect of the hot water extraction in the extractability of carbon (compared to the cold water extraction) was analysed using a Paired Sample Wilcoxon Signed Rank Test. The correlation between the different 
analytical methods was tested using the Spearman Rank and assessing the significance of the resulted Spearman Correlation Coefficient (Minitab 16 for Windows. Minitab Inc., State College, PA, USA). Linear regressions of the Spearman Correlations were also plotted (SigmaPlot 12.0 for Windows. Systat Software Inc., San Jose, CA, USA). Differences of $\mathrm{p}<0.05$ were considered statistically significant.

\section{Results and discussion}

\subsection{Soil characteristics}

The majority of CC-UK soils had sandy texture, with a relatively high proportion of silt (Table 2). The only exception was CC-UK-2, although the sand proportion was quite close to that of silt. This texture was similar to that of CC-ES-1 and CC-ES-2, although CC-ES-3 had a higher proportion of silt and higher proportion of clay than of sand. All the OG soils presented a texture of a majority of silt (56.7-59.5\%), followed by clay. It is worth considering that silt is the most erodible fraction (Table 2). $\mathrm{pH}$ in the UK soils was generally acid, although GS-UK-1 and CC-UK-1 had values between 3.58-5.66 and CC-UK-2 had values close to 7. ES soils had generally higher values, ranging from 5.53-6.98 (Table 2). Some authors have related $\mathrm{pH}$ and measurement of aromatics (Weishar et al., 2003). GS-UK-1 has the lowest pH (3.58) and is the one with the highest aromatics content and highest HWC.

\subsection{Total extractable carbon by cold and hot extractions}

CWC and HWC measurement results are in Table 3. HWC extracted significantly more carbon $(\mathrm{P}<0.01)$ than $\mathrm{CWC}$, thus proved to be a more exhaustive extraction method. The increases in the values ranged from $161-605 \%$. This was equivalent to higher values by a factor between 3 and 7 respectively. The most significant increase was obtained in GS-UK-1. Gregorich et al. (2003) obtained a similar trend in maize-cropped soils of Ottawa, Canada, and found HWC exceeding CWC by a factor of two. 

than CWC by a factor that varied from 4 to 6 in surface horizons of forest soils in SE Germany.

A correlation analysis was run to assess whether the $\mathrm{C}$ extractability differed between the different soils and locations. The correlation resulted to be high $(\mathrm{Rs}=0.91, \mathrm{p}<0.01)$. Wang and Wang (2007) found a similar correlation $(r=0.93, p=<0.01)$ in forest oxisols of Southern China. Klose and Makeschin (2003) also found that HWC and CWC increased with the same proportion in forest soils of NE Germany. On the other hand, Ghani et al. (2003) found a positive but poor correlation. HWC and CWC data were compared with SOM (measured by LOI) to assess which of the two extraction methods would imply a higher correlation with the organic matter from the samples (Table 4). HWC implied a higher correlation with SOM measured with LOI $(\mathrm{Rs}=0.70, \mathrm{p}<0.05)$ than $\mathrm{CWC}(\mathrm{Rs}=0.55)$. Despite the fact that the correlation between CWC and SOM was lower than that of HWC; other authors have found even poorer correlations. For instance, Van Migroet et al. (2005) found $\mathrm{r}^{2}$ of 0.2 in forest soils in Utah, USA.

3.3. Quality of cold-water extractable carbon using UV-Vis and Fluorescence

Cold-water extractable carbon (CWC) data was compared with UV-Vis and Correlation was calculated to evaluate the quality and reproducibility of CWC using optical techniques (Table 4).

361 There were high correlation patterns between CWC and SUVA-254 $(R s=0.82, p<0.05)$ although not between CWC and FI (Rs=-0.29), where the slight correlation that could be appreciated was inverse. Chow (2006) obtained a worse correlation between CWC and SUVA-254 $\left(\mathrm{R}^{2}=0.38\right)$, whereas that of Van Migroet et al. (2005) was even lower 
$365\left(\mathrm{R}^{2}=0.01\right)$. As Weishar et al. (2003) point out; some authors have found conflicting

366 conclusions when using SUVA-254 to determine the aromaticity of DOC.

367
3.4 . Quality of hot-water extractable carbon using UV-Vis and Fluorescence

correlation than CWC. As it can be seen in Table 4, there is a high correlation (Rs=0.88, $\mathrm{p}<0.001$ ) between HWC and SUVA- 254 whereas that of HWC with FI is not as significant $(\mathrm{Rs}=-0.53)$. In both cases, HWC was more significantly correlated to the results obtained with fluorescence and SUVA-254 than CWC.

\subsection{EEM spectra general characteristics}

A set of reference fluorescence spectra has been represented in Figure 1. As it can be seen in Figure 1.a and 1.b, the two soils with the highest $\%$ aromatics measured with ${ }^{1} \mathrm{H}-\mathrm{NMR}$ as well as high SUVA-254 and HWC values (GS-UK-1 and CC-UK-1) showed strong peaks C (10-12 RUs), which indicate UVA-excited humic peaks as described by Coble (1996). They also showed weak peaks A.

On the other hand, Figure 1.c. represents the soil with the highest FI, but lowest \% aromatic measured with ${ }^{1} \mathrm{H}-\mathrm{NMR}$ as well as comparatively low values of SUVA-254 (CC-ES-1). The EEM spectrum of this soil is very different from the ones represented in Figures 1.a and 1.b, with a strong peak A or UVC-excited (8 RUs), and weak peaks C and $\mathrm{T}$. The presence of the latter indicates biological activity.

\section{6. $\quad$ Relationship between optical measures and NMR}

The aromaticity of isolated fulvic acid samples was calculated as the ratio of the area of aromatic hydrogen region to the total area of the ${ }^{1} \mathrm{H}-\mathrm{NMR}$ spectrum (\% aromaticity). An analogous method was used to calculate the ratio of the area of aliphatic hydrogen and carbohydrate hydrogen regions. 
As it can be seen in Figure 2, the aromatic hydrogen region is situated in a chemical shift of 6-8ppm by frequency. On the other hand, the carbohydrate hydrogen and aliphatic hydrogen regions are situated in a chemical shift of 3-4.2 ppm and 0.5-3 ppm respectively. For Figure 2, the two soils with the highest $\%$ aromatics were chosen for representation purposes (GS-UK-1 and CC-UK-1).

Results of these measurements can be found in Table 3, along with the results from the optical techniques. Correlation analyses were conducted comparing the results from all of them (Table 4).

The largest carbon fraction of the UK soils was carbohydrates. The same trend was found in the CC-ES soils, but not in the OG-ES soils, where the largest carbon fraction was aliphatics.

400

The proportion of aromatics of the UK soils ranged from $3.91 \%-5.98 \%$, whereas for the CC-ES and OG-ES soils, it ranged from $2.40-3.47 \%$ and $3.90 \%-4.33 \%$ respectively. As these were taken from samples in the first horizon of each soil, the low level of aromaticity can be explained by the fact that plant residues may have accumulated in the surface, while microorganisms did not have enough capacity to decompose them. As Cardoza et al. (2004) point out, NMR is a powerful tool for investigating humic substances interactions at the molecular level. Aromatics have positive correlations for $\mathrm{SUVA}_{-254}, \mathrm{CWC}$ and $\mathrm{HWC}$ but are inversely correlated to FI. Correlations are high for aromatics compared with SUVA- 254 and HWC (Figures 3 and 4. Rs of 0.95 and 0.90 respectively; $p<0.001$ ), but not as good for

410 FI (Figure 5). The correlation between aromatics and CWC, although significant, is not as strong as the one with $\mathrm{HWC}(\mathrm{Rs}=0.74, \mathrm{p}<0.05)$. Weishaar et al. $(2003)$ found that 412 SUVA- $_{254}$ is a good predictor of the humic fraction (higher SUVA-254 indicates higher humic acid content and molecular weight in DOM solutions) and the general chemical 
properties of HWC, although it does not predict the reactivity of HWC from different types of source materials nor information of the individual molecules of samples unless these are humic substances (Chin et al., 1997; Weishar et al., 2003). They obtained a good correlation between SUVA- 254 and aromaticity determined by ${ }^{13} \mathrm{C}-\mathrm{NMR}(\mathrm{R}=0.97)$, which was slightly higher than ours. Yeh et al. (2014) also found a high correlation between SUVA- 254 measurements and the aromatic fraction of samples of organic matter of river sediments of Taiwan. Jamieson et al. (2014) found that higher SUVA-254 implied higher aromaticity in biochar from sugar maple, thus demonstrating that this effect is currently studied when characterising organic material with a high recalcitrance and that is able to retain carbon for thousands of years, due to its stability (Lehmann, 2007).

According to McKnight (2001) and other authors (Rodríguez et al., 2014; Wei et al., 2014), there is a correlation between the FI values and those from methods that indicate the aromaticity of humic substances such as the ratio of the aromatic carbon region area in the total NMR spectra and SUVA-254. This pattern was observed in our soils, with negative correlations between FI and these 2 parameters $(\mathrm{Rs}=-0.63$ and $\mathrm{Rs}=-0.52$ respectively), although only the trend with the aromatic carbon region area in the total NMR spectra was statistically significant $(\mathrm{p}<0.05)$.

Kim et al. (2006) and Rodríguez et al. (2014) indicated that differences in the FI higher than 0.1 would imply significant differences in the aromaticity of the samples. If this assumption is applied to our case, CC-UK-2 has differences in its aromaticity with GSUK-1 but not with CC-UK-1. CC-ES-2 has a different aromaticity than CC-ES-1 and CC-ES-3. In the same way, OG-ES-1 has differences with OG-ES-2 and OG-ES-3. When all the types are compared, there are combinations of differences in the aromaticity but a single pattern cannot be obtained. 
439 Given the results above, the regressions between the aromatic carbon region measured 440 with ${ }^{1} \mathrm{H}-\mathrm{NMR}$ and SUVA-254 and HWC are powerful. The equations we obtained can 441 explain very significantly the relationship between these variables $(p<0.001$ for the 442 results of ${ }^{1} \mathrm{H}-\mathrm{NMR}$ predicted with $\mathrm{SUVA}_{-254}$ and $\mathrm{p}<0.01$ if they are predicted using 443 HWC). These equations (Figure 3 and Figure 4) could therefore be used to predict the 444 aromaticity of water-extractable carbon.

445 The regression of the aromaticity measured with ${ }^{1} \mathrm{H}-\mathrm{NMR}$ with FI, although significant 446 ( $\mathrm{p}<0.05)$, did not have the same level of confidence as the one with HWC and SUVA447 254. As it can be seen in Figure 5, an outlier was identified in the Regression analysis (FI 448 value of CC-ES-3). Figure 5 showed how the regression model improved when the 449 outlier was removed from the analysis $(\mathrm{Rs}=-0.98)$. The linear regression equation that 450 resulted after the elimination of the outlier is able to explain the ${ }^{1} \mathrm{H}-\mathrm{NMR}$ values using 451 FI with a very high significance $(\mathrm{p}<0.001)$.

452 However, according to McKnight (2001), the FI would not be sufficient to estimate aromaticity and other techniques are necessary (e.g. SUVA-254), as geological processes 454 can alter aromaticity without changing the FI.

455 SUVA- 254 did not demonstrate a particularly strong correlation with FI $(\mathrm{Rs}=-0.52$, Table 456 4). The correlation was negative (higher SUVA-254 led to lower FI) which coincides 457 with authors like Kothawala et al. (2012) with minerals soils collected across Canada although their trend is less clear than in the study of other authors such as Williams et 459 al. (2010), where the slope is more pronounced. The correlation of Williams et al. 460 (2010) was similar to ours ( $r=-0.57$ in their study and $\mathrm{Rs}=-0.52$ in ours), although the statistical analysis in their case was the Pearson correlation, as their data followed a normal distribution. Hassouna et al. (2012) found a negative correlation as well, with slightly higher correlation in Mediterranean calcareous soils ( $r=-0.69)$. As in the case 
described in Figure 5, if the same outlier was removed, the correlation improved significantly (Rs=-0.98) and the equation of the linear regression explained with a very high degree of significance $(\mathrm{p}<0.001)$ the relation between SUVA-254 and FI. Analogously, the same outlier could be removed in the analysis of HWC vs. FI, obtaining a significant correlation between them $(\mathrm{Rs}=-0.88)$. A linear regression model explains significantly $(\mathrm{p}<0.01)$ the relationship between HWC and FI and therefore similar conclusions can be stated as in the case of the correlation of SUVA-254 to FI. Given the strong intrinsic relationships between the results of SUVA-254, HWC and FI; and how they are able to predict the proportion of aromaticity measured with ${ }^{1} \mathrm{H}-\mathrm{NMR}$, we can conclude that UV-Vis absorbance and fluorescence spectroscopy can be used to characterise the aromaticity of carbon and may be a plausible substitute for ${ }^{1} \mathrm{H}-\mathrm{NMR}$, given that they are more cost-effective. Other authors such as Zornoza et al. (2008, 2015) demonstrated the effectiveness of spectroscopy (near infrared reflectance spectroscopy in their study) as an accurate, cost- and time-effective method for predicting and/or estimating soil biogeochemical properties and other soil parameters. Correlations between aliphatics and the data from the optical measures and CWC/HWC were poor (Table 4), although slight trends can be observed for SUVA-254, FI and CWC. In these cases, the correlation was positive for FI and CWC but negative for SUVA-254. Correlations were also poor between carbohydrates and the data from the optical measures and $\mathrm{HWC} / \mathrm{CWC}$, with only one trend detected. This was the inverse correlation $(\mathrm{Rs}=-0.35)$ between HWC and carbohydrates. very few trends detected. Of the trends detected, HIX was positively correlated with FI $(\mathrm{Rs}=0.52)$. It is worth noting that BIX was positively correlated with carbohydrates but inversely correlated to aliphatics ( $\mathrm{Rs}=0.31$ and -0.31 respectively), whereas the trend 
was the contrary for HIX (Rs=-0.28 and 0.22). A similar trend than ours was also found

490

491

492

493

494

495

496

497

498

499

500

501

502

503

504

505

506

507

508

509

510

511

512

by Kalbitz et al. (2003) between HIX and carbohydrates in forest soils, arable soils and a fen area; although theirs was stronger $\left(\mathrm{r}^{2}=0.81\right)$. Williams et al. (2010) studied the correlation between HIX and SUVA-254 in watershed from mixed land use in Canada. They obtained a positive correlation $(\mathrm{r}=0.74)$, whereas our correlation was negative. On the other hand, Yeh et al. (2014) did not find a clear trend between SUVA-254 and HIX. The significance of our comparison between SUVA-254 and HIX values is extremely low and therefore robust conclusions on this issue cannot be stated. Bu et al. (2010) compared HWC and HIX in various soils with different vegetation types in Wuyi Mountain (SE China), obtaining a poor negative correlation, just like ours. However, Kalbitz et al. (2003) found a strong correlation between the aromatic fraction of DOM and $\operatorname{HIX}\left(\mathrm{r}^{2}=0.80\right)$.

Yeh et al. (2014) calculated BIX as well, obtaining that higher SUVA-254 values implied lower BIX values, which coincides with our comparison in this case, although its significance is not relevant enough to establish a robust conclusion.

Plotting the results from Birdwell and Engel (2010) for FI, HIX, and BIX did not led to significant correlations, which is similar to our results and, along with the authors commented above, demonstrate that a number of studies have found difficulties when correlating HIX and BIX to other parameters.

\section{Conclusions}

Different techniques to measure the quantity and quality of SOM were tested in cambisols from very different climatic locations and under different cropping systems. HWC extracted a higher amount and carbon than CWC, and correlated better with the $\%$ SOM (LOI) than CWC. 
513 SUVA-254 and HWC correlated significantly with the proportion of aromatics measured

514 with ${ }^{1} \mathrm{H}-\mathrm{NMR}$, demonstrating their complementary nature. Linear regression models

515 fitted to the data were able to explain the relationship between the specific fraction of

516 aromatics measured with ${ }^{1} \mathrm{H}-\mathrm{NMR}$ and SUVA-254 and HWC, and therefore allow the

517 aromatic fraction to be estimated at lower cost using SUVA-254 and HWC.

518 A linear regression model was also able to explain the relationship between ${ }^{1} \mathrm{H}-\mathrm{NMR}$

519 measurements and FI, after an outlier was removed.

520 BIX and HIX were not useful indexes for our purposes, as they did not correlate well to

521 the carbon fractions measured with ${ }^{1} \mathrm{H}-\mathrm{NMR}$ or with FI, SUVA-254, or HWC.

522 The EEM spectra showed a difference in the peak types that appeared in the CC-UK

523 soils and in the CC-ES soil. The fact that figures 1.a and 1.b showed a stronger peak C

524 and figure 1.c. showed a stronger peak A indicated subtle qualitative differences in their

525 humic fractions. This could have been caused by the different soil management (more

526 intense agricultural activity in CC-ES-1). More work will be needed to confirm this.

527 In view of our results, optical measures have a potential, in combination, to predict the

528 aromatic fraction of SOM without the need of expensive and time consuming

529 techniques like ${ }^{1} \mathrm{H}-\mathrm{NMR}$; which could be very useful when the equipment is not

530 available or in instances when a high number of samples need to be analysed

531 simultaneously.

\section{5. Acknowledgments}

533 We thank J.M. Calero and M. Bell for their contribution to improve this paper.

\section{6. References}

535 Aemet, 2014. Historic series of climatic data 1971-2000. Agencia Estatal de

536 Meteorología (Spanish State Meteorological Agency). Available at: 
$538=5402 \& \mathrm{k}=$ and $\left[\right.$ Accessed: $08^{\text {th }}$ August 2014].

539 Agren, G.I., Bosatta, E., 2002. Reconciling differences in predictions of temperature 540 response of soil organic matter. Soil Biol. Biochem. 34, 129-132.

541 Alburquerque, J.A., Calero, J.M., Barrón, V., Torrent, J., Campillo, M.C., Gallardo, A.,

542 Villar, R., 2014. Effects of biochars produced from different feedstocks on soil 543 properties and sunflower growth. J. Plant Nutr. Soil Sci. 177, 16-25.

544 Batjes, N. H., 2014. Projected changes in soil organic carbon stocks upon adoption of

545 recommended soil and water conservation practices in the upper Tana River catchment, 546 Kenya. Land Degrad. Dev. 25, 278-287.

547 Bell, M., Lawrence, D., 2009. Soil carbon sequestration - Myths and mysteries.

548 Department of Primary Industries and Fisheries, Queensland, Australia. Available at:

549 http://www.futurebeef.com.au/wp-content/uploads/2011/09/Soil-Carbon-Sequestration-

550 Report.pdf [Accessed: $8^{\text {th }}$ November 2014].

551 Birdwell, J.E., Engel, A.S., 2010. Characterization of dissolved organic matter in cave

552 and spring waters using UV-Vis absorbance and fluorescence spectroscopy. Org.

553 Geochem. 41, 270-280.

554 Brevik, E.C., 2009. Soil Health and Productivity, in: Verheye, W. (Ed.), Soils, Plant

555 Growth and Crop Production; Encyclopaedia of Life Support Systems (EOLSS),

556 Developed under the Auspices of the UNESCO. EOLSS Publishers, Oxford, UK.

557 Available at: http://www.eolss.net [Accessed 10 ${ }^{\text {th }}$ November 2014].

558 Brevik, E. C., 2012. Soils and climate change: Gas fluxes and soil processes. Soil

559 Horiz. 53, 12-23. 

characterization of hot-water extractable organic matter from soils under four different vegetation types along an elevation gradient in the Wuyi Mountains. Geoderma 159, $139-146$.

Cardoza, L.A., Korir, A.K., Otto, W.H., Wurrey, C.J., C.K. Larive, C.K., 2004. Applications of NMR spectroscopy in environmental science. Prog. Nucl. Mag. Res. Sp. 45, 209-238.

Cerdà, A., 1998. The influence of aspect and vegetation on seasonal changes in erosion under rainfall simulation on a clay soil in Spain. Can. J. Soil. Sci. 78, 321-330.

Cerdà, A., 2000. Aggregate stability against water forces under different climates on agriculture land and scrubland in southern Bolivia. Soil Till. Res. 57, 159-166.

573 Chen, J., LeBoef, E.J., Dai, S., Gu, B., 2003. Fluorescence spectroscopic studies of 574 natural organic matter fractions. Chemosphere 50, 639-647.

575 Chen, Y., Day, S.D., Wick, A.F., Strahm, B.D., Wiseman, P.E., Daniels, W.L., 2013.

576 Changes in soil carbon pools and microbial biomass from urban land development and 577 subsequent post-development soil rehabilitation. Soil Biol. Biochem. 66, 38-44.

578 Chin Y.P., Aiken, G.R., Danielsen, K.M., 1997. Binding of pyrene to aquatic and 579 commercial humic substances: the role of molecular weight and aromaticity, Environ. Sci. Technol. 31, 1630-1635. 
581 Chow, A.T., 2006. Disinfection byproduct reactivity of aquatic humic substances

582 derived from soils. Water Res. 40, 1426-1430.

583 Coble, P., 1996. Characterization of marine and terrestrial DOM in seawater using 584 excitation-emission matrix spectroscopy. Mar. Chem. 51, 325-346.

585 Cory, R.M., Miller, M.P., McKnight, D.M., Guerard, J.J., Miller, P.L., 2010. Effect of 586 instrument-specific response on the analysis of fulvic acid fluorescence spectra. Limnol. 587 Oceanogr. Meth. 8, 67-78.

588 Dungait, J., Hopkins, D., Gregory, A.S., Whitmore, A.P., 2012. Soil organic matter 589 turnover is governed by accessibility not recalcitrance. Glob. Chang. Biol. 18, 17815901796.

591 Fernández-Romero, M.L., Lozano-García, B., Parras-Alcántara, L., Collins, C.D., 592 Clark, J.M., 2014. Effects of land management on different forms of soil carbon in olive 593 groves in Mediterranean areas. Land Degrad. Dev. (In press) DOI: 10.1002/ldr.2327.

594 Fischlin, A., Midgley, G.F., Price, J., Leemans, R., Gopal, B., Turley, C., Rounsevell, 595 M., Dube, P. Tarazona, J., Velichko, A., 2007. Ecosystems, their properties, goods, and 596 services, in: M. L., Canziani, O. F., Palutikof, J. P., van der Linden, P. J. \& Hanson, C. 597 E. (Eds.), Climate Change: Impacts, Adaptation and Vulnerability. Contribution of 598 Working Group II to the Fourth Assessment Report of the Intergovernmental Panel on 599 Climate Change. Cambridge University Press, Cambridge, UK, pp. 211-272. ISBN: $600978052188010-7$.

601 Fuentes, M., González-Gaitano, G., García-Mina, J.M., 2006. The usefulness of UV602 visible and fluorescence spectroscopies to study the chemical nature of humic 603 substances from soils and composts. Org. Geochem. 37, 1949-1959. 
604 García-Gil, J.L., Plaza, C., Soler-Rovira, P., Polo, A., 2000. Long-term effects of 605 municipal solid waste compost application on soil enzyme activities and microbial 606 biomass. Soil Biol. Biochem. 32, 1907-1913.

607 Ghani, A., Dexter, M. \& Perrott, K.W., 2003. Hot-water extractable carbon in soils: a 608 sensitive measurement for determining impacts of fertilization, grazing and cultivation. 609 Soil Biol. Biochem. 35, 1231-1243.

610 González-Pérez, M., Milori, D.M.B.P., Colnago, L.A., Martin-Neto, L., Melo, W.J., 611 2007. A laser-induced fluorescence spectroscopic study of organic matter in a Brazilian 612 Oxisol under different tillage systems. Geoderma 138, 20-24.

613 Gregorich, E.G., Beare, M.H., Stoklas, U., St-Georges, P., 2003. Biodegradability of 614 soluble organic matter in maize-cropped soils. Geoderma 113, 237-252.

615 Hassouna, M., Théraulaz, F., Massiani, C., 2012. Production and elimination of water 616 extractable organic matter in a calcareous soil as assessed by UV/Vis absorption and 617 fluorescence spectroscopy of its fractions isolated on XAD-8/4 resins. Geoderma 189$618190,404-414$.

619 Helal, A.A., Murad, G.A., Helal, A.A., 2011. Characterization of different humic 620 materials by various analytical techniques. Arab. J. Chem. 4, 51-54.

621 Hemminga, M.A., Buurman, P., 1997. Editorial: NMR in soil science. Geoderma 80, $622 \quad 221-224$.

623 Henderson, R.K., Baker, A., Murphy, K.R., Hamblya, A., Stuetz, R.M., Khan, S.J., 624 2009. Fluorescence as a potential monitoring tool for recycled water systems: a review.

625 Water Res. 43, 863-881. 
626 Hieri, O., Lotter, A.F., Lemke, G., 2001. Loss on Ignition as a method for estimating organic and carbonate content in sediments: Reproducibility and comparability of 628 results. J. Paleolimnol. 25, 101-110.

631 Geochem. 40, 706-719.

Hur, J., Kim, G., 2009. Comparison of the heterogeneity within bulk sediment humic substances from a stream and reservoir via selected operational descriptors.

634 Chemosphere 75, 483-490.

Hur, J., Park, S.W., Kim, M.C., Kim, H.S., 2013. Enhanced binding of hydrophobic organic contaminants by microwave-assisted humification of soil organic matter.

637 Chemosphere 93, 2704-2710. dissolved organic matter using UV-visible absorption and excitation-emission

640 fluorescence spectroscopies. Chemosphere 103, 197-204.

641 Kalbitz, K., Schmerwitz, J., Schwesig, D., Matzner, E., 2003. Biodegradation of soil 642 derived dissolved organic matter as related to its properties. Geoderma 113, 273-291.

643 Kim, H.C., Yu, M.J., Han, I., 2006, Multi-method study of the characteristic chemical 644 nature of aquatic humic substances isolated from the Han River, Korea. Appl.

645 Geochem. 21, 1226-39.

646 Kleber, M., 2010. What is recalcitrant soil organic matter? Environ. Chem. 7, 320-332. 
647 Kleber, M., Johnson, M. G., 2010. Advances in understanding the molecular structure 648 of soil organic matter: implications for interactions in the environment. Adv. Agron. $649106,77-142$.

650 Klose, S., Makeschin, F., 2003. Effects of past fly ash deposition on the forest floor 651 humus chemistry of pine stands in Northeastern Germany. For. Ecol. Manage. 183, $652 \quad 113-126$.

653 Koarashi, J., Iida, T., Asano, T., 2005. Radiocarbon and stable carbon isotope 654 compositions of chemically fractionated soil organic matter in a temperate-zone forest. 655 J. Environ. Radioact. 79, 137-56.

656 Korak, J.A., Dotson, A.D., Summers, R.S., Rosario-Ortiz, F.L., 2014. Critical analysis 657 of commonly used fluorescence metrics to characterize dissolved organic matter. Water 658 Res. 49, 327-338.

659 Kothawala, D.N., Roehm, C., Blodau, C., Moore, T.R., 2012. Selective adsorption of 660 dissolved organic matter to mineral soils. Geoderma 189-190, 334-342.

661 Kwiatkowska, J., Provenzano, M., Senesi, N., 2008. Long term effects of a brown coal662 based amendment on the properties of soil humic acids. Geoderma 148, 200-205.

663 Lal, R., 2004. Soil carbon sequestration to mitigate climate change. Geoderma 123, 166422.

665 Landgraf, D., Leinweber, P., Makeschin, F., 2006. Cold and hot water-extractable 666 organic matter as indicators of litter decomposition in forest soils. J. Plant Nutr. Soil 667 Sci. 169, 76-82.

668 Lehmann, J., 2007. Bio-energy in the black. Front. Ecol. Environ. 5, 381-387. 
669

670

671

672

673

674

675

676

677

678

679

680

681

682

683

684

685

686

687

688

689

690

691

Leifeld J., Kogel-Knabner I., 2005. Soil organic matter fractions as early indicators for carbon stock changes under different land-use? Geoderma 124, 143-155.

Li, L.J., Han, X.Z., You, M.Y., Yuan, Y.R., Ding, X.L., Qiao, Y.F., 2013. Carbon and nitrogen mineralization patterns of two contrasting crop residues in a Mollisol: Effects of residue type and placement in soils. Eur. J. Soil Biol. 54, 1-6.

Luke, J. K., Brevik, E. C., Wood, G. L., 2009. Evaluation of loss on ignition method for determining organic matter of South Georgia soils. Soil Surv. Hor. 50, 83-85.

Martins, T., Saab, S.C., Milori, D.M.B.P., Brinatti, A.M., Rosa, J.A., Cassaro, F.A.M., Pires, L.F., 2011. Soil organic matter humification under different tillage managements evaluated by Laser Induced Fluorescence (LIF) and C/N ratio. Soil Till. Res. 111, 231235.

McKnight, D.M., Boyer, E.W., Westerhoff, P., Doran, P., Kulbe, T., Andersen, D., 2001. Spectrofluorimetric characterization of dissolved organic matter for indication of precursor organic material and aromaticity. Limnol. Oceanogr. 46, 38-48.

MIT, 2008. Things to know before you begin operating an NMR. Department of Chemistry. Instrumentation Facility. Massachusetts Institute of Technology. Available at: http://web.mit.edu/speclab/www/PDF/DCIF-Things-2-know-NMR-m08.pdf [Accessed 10 $0^{\text {th }}$ June 2014].

Novara, A., Gristina, L., Saladino, S.S., Santoro, A., Cerdà, A., 2011. Soil erosion assessment on tillage and alternative soil managements in a Sicilian vineyard. Soil Till. Res. 117, 140-147.

Ohno, T., 2002. Fluorescence inner-filtering correction for determining the humification index of dissolved organic matter. Environ. Sci. Technol. 36, 742-746. 
692

693

694

695

696

697

698

699

700

701

702

703

704

705

706

707

708

709

710

711

712

713

714

Olk, D.C., Gregorich, E.G., 2006. Overview of the symposium proceedings,

"Meaningful pools in determining soil carbon and nitrogen dynamics". Soil Sci. Soc.

Am. J. 70, 967-974.

Paradelo R., Barral, M.T., 2013. Influence of organic matter and texture on the compactability of Technosols. Catena 110, 95-99.

REDIAM, 2007. Historical series of meteorological data 1953-2007. Red de

Información Ambiental de Andalucía (Andalusian Network of Environmental Information). Seville, Spain.

Rodríguez, F.J., Schlenger, P., García-Valverde, M., 2014. A comprehensive structural evaluation of humic substances using several fluorescence techniques before and after ozonation. Part I: Structural characterization of humic substances. Sci. Total Environ. 476-477, 718-730.

Rose, M.T., Patti, A.F., Little, K.R., Brown, A.L., Jackson, W.R., Cavagnaro, T.R., 2014. Chapter Two - A Meta-Analysis and Review of Plant-Growth Response to Humic Substances: Practical Implications for Agriculture. Adv. Agron. 124, 37-89.

Saab, S.C., Martin-Neto, L., 2007. Condensed aromatic rings and $\mathrm{E}_{4} / \mathrm{E}_{6}$ ratio: humic acids in gleysoils studied by NMR cp/mas ${ }^{13} \mathrm{C}$, and dipolar dephasing. Quim. Nova 30, $260-263$.

Saha, D., Kukal, S.S., Bawa, S.S., 2014. Soil organic carbon stock and fractions in relation to land use and soil depth in the degraded Shiwaliks Hills of lower Himalayas. Land Degrad. Dev. 25, 407-416.

Salehi, M.H., Beni, O.H., Harchegani, H.G., Borujeni, I.E., 2011. Refining Soil Organic Matter Determination by Loss-on-Ignition. Pedosphere 21, 473-482. 
715 Schmidt, M.W.I., Torn, M.S., Abiven, S., Dittmar, T., Guggenberger, G., Janssens, I.A.,

716 Kleber, M., Kögel-Knabner, I., Lehmann, J., Manning, D.A.C., Nannipieri, P., Rasse,

717 D.P., Weiner, S., Trumbore, S.E., 2011. Persistence of soil organic matter as an 718 ecosystem property. Nature 478, 49-56.

719 Schrumpf, M., Kaiser, K., 2015. Large differences in estimates of soil organic carbon

720 turnover in density fractions by using single and repeated radiocarbon inventories.

721 Geoderma 239-240, 168-178.

722 Sellami, F., Hachicha, S., Chtourou, M., Medhioub, K., Ammar, E., 2008. Maturity

723 assessment of composted olive mill wastes using UV spectra and humification

724 parameters. Bioresource Technol. 99, 6900-6907.

725 Senesi, N., D’Orazio, V., 2005. Fluorescence spectroscopy, in: Hillel, D. (Ed.),

726 Encyclopedia of Soils in the Environment. Academic Press, Elsevier Science, pp. 35-

727 52. ISBN: 978-0-12-348530-4.

728 Skoog, D.A., Holler, F.J., Crouch, S.R., 2007. Principles of Instrumental Analysis.

729 Brooks/Cole Publishing. Belmont, CA, USA. ISBN: 978-0-495-01201-6.

730 Sparks, D.L., 2003. Environmental Soil Chemistry, second ed. Academic Press,

731 Elsevier Science, San Diego, USA. ISBN 0-12-656446-9.

732 Srinivasarao, CH., Venkateswarlu, B., Lal, R., Singh, A. K., Kundu, S., Vittal, K. P.

733 R., Patel, J. J., Patel, M. M., 2014. Long-term manuring and fertilizer effects on

734 depletion of soil organic carbon stocks under pearl millet- cluster bean-castor rotation in

735 Western India. Land Degrad. Dev. 25, 173-183. 
736 Sun, W.L., Ni, J.R., Xu, N., Sun, L.Y., 2007. Fluorescence of sediment humic substance

737 and its effect on the sorption of selected endocrine disruptors. Chemosphere 66, 700738707.

739 Sutton, R., Sposito, G., 2005. Molecular Structure in Soil Humic Substances: The New 740 View. Environ. Sci. Technol. 39, 9009-9015.

741 Tang, Z., Yu, G., Liu, D., Xu, D., Shen, Q., 2011. Different analysis techniques for

742 fluorescence excitation-emission matrix spectroscopy to assess compost maturity.

743 Chemosphere 82, 1202-1208.

744 Trumbore, S., 1997. Potential responses of soil organic carbon to global

745 environmental change. P. Natl. Acad. Sci. USA 94, 8284-8291.

746 Trumbore, S., 2000. Age of soil organic matter and soil respiration: Radiocarbon

747 constraints on belowground C dynamics. Ecol. Appl. 10, 399-411.

748 Uchida, Y., Nishimurab, S., Akiyama, H., 2012. The relationship of water-soluble

749 carbon and hot-water-soluble carbon with soil respiration in agricultural fields. Agr.

750 Ecosyst. Environ. 156, 116-122.

751 UK Met Office, 2014. Reading 1981-2010 climatic averages. Available at:

752 http://www.metoffice.gov.uk/public/weather/climate/gcpk9wzwz [Accessed $8^{\text {th }}$

$753 \quad$ November 2014].

754 Van Miegroet, H., Boettinger, J.L., Baker, M.A., Nielsen, J., Evans, D., Stum, A., 2005.

755 Soil carbon distribution and quality in a montane rangeland-forest mosaic in northern

756 Utah. Forest Ecol. Manag. 220, 284-299. 
757 Wang, Q.K., Wang S.L., 2007. Soil organic matter under different forest types in 758 Southern China. Geoderma 142, 349-356.

759 Wei, Z., Zhao, X., Zhu, C., Xi, B., Zhao, Y., Yu, X., 2014. Assessment of humification 760 degree of dissolved organic matter from different composts using fluorescence 761 spectroscopy technology. Chemosphere 95, 261-267.

762 Weishaar, J.L., Aiken, G.R., Bergamaschi, B.A., Fram, M.S., Fujii, R., Mopper, K., 763 2003. Evaluation of Specific Ultraviolet Absorbance as an Indicator of the Chemical 764 Composition and Reactivity of Dissolved Organic Carbon. Environ. Sci. Technol. 37, $765 \quad 4702-4708$.

766 Williams, C.J., Yamashita, Y., Wilson, H.F., Jaffé, R., Xenopoulos, M.A., 2010.

767 Unravelling the role of land use and microbial activity in shaping dissolved organic 768 matter characteristics in stream ecosystems. Limnol. Oceanogr. 55, 1159-1171.

769 Xue, S., Li, P., Liu, G., Li, Z., Zhang, C., 2013. Changes in Soil Hot-Water Extractable $770 \mathrm{C}, \mathrm{N}$ and P Fractions During Vegetative Restoration in Zhifanggou Watershed on the 771 Loess Plateau. J. Integr. Agr. 12, 2250-2259.

772 Yeh, Y.L., Yeh, K.J., Hsu, L.F., Yu, W.C, Lee, M.H., Chen, T.C., 2014. Use of

773 fluorescence quenching method to measure sorption constants of phenolic

774 xenoestrogens onto humic fractions from sediment. J. Hazard. Mater. 277, 27-33.

775 Zhao, G., Mu, X., Wen, Z., Wang, F., Gao, P., 2013. Soil erosion, conservation, and 776 eco-environment changes in the Loess Plateau of China. Land Degrad. Dev. 24, 499777510. 
Zhao, M., Zhou, J., Kalbitz, K., 2008. Carbon mineralization and properties of waterextractable organic carbon in soils of the south Loess Plateau in China. Eur. J. Soil Biol. 44, 158-165.

Zornoza, R., Guerrero, C., Mataix-Solera, J., Scow, K.M., Arcenegui, V., MataixBeneyto, J., 2008. Near infrared spectroscopy for determination of various physical, chemical and biochemical properties in Mediterranean soils. Soil Biol. Biochem. 40, $1923-1930$.

Zornoza, R., Acosta, J. A., Bastida, F., Domínguez, S. G., Toledo, D. M., Faz A., 2015. Identification of sensitive indicators to assess the interrelationship between soil quality, management practices and human health. Soil 1, 173-185.

Zsolnay, A., Baigar, E., Jimenez, M., Steinweg, B., Saccomandi, F., 1999.

Differentiating with fluorescence spectroscopy the sources of dissolved organic matter in soils subjected to drying. Chemosphere $38,45-50$.

\section{$\underline{\text { Figure captions }}$}

Figure 1. EEM plots from: a) GS-UK-1; b) CC-UK-1; c) CC-ES-1

Figure 2. Liquid state ${ }^{1} \mathrm{H}-\mathrm{NMR}$ spectra from: a) GS-UK-1; b) CC-UK-1

Figure 3. Correlation between \% Aromatics and SUVA-254. A linear regression model was calculated to explain the relationship between the variables. The equation was y [\% Aromatics $]=0.250+0.950 \times\left[\mathrm{SUVA}_{-254}\right], \mathrm{p}<0.001$

Figure 4. Correlation between \% Aromatics and HWC. A linear regression model was calculated to explain the relationship between the variables. The equation was y [\% Aromatics $]=0.500+0.900 \times[\mathrm{HWC}],(\mathrm{p}<0.01)$ 
800 Figure 5. Correlation between \% Aromatics and FI. A linear regression model was

801 calculated to explain the relationship between the variables. The equation was y [\%

802 Aromatics $]=8.17-0.633 \times[\mathrm{FI}],(\mathrm{p}<0.05)$, represented by the solid line. The removal

803 of an outlier resulted in the equation: $\mathrm{y}[\%$ Aromatics $]=8.89-0.976 \times[\mathrm{FI}]$, which

804 explained the relationship with a higher significance $(\mathrm{p}<0.001)$. The second equation is

805 represented by the dashed line 